\title{
Dealing with Challenges of Implant Failure and Complications: Case Report
}

\author{
Prashant Awasthi ${ }^{1}$, Subrata Roy ${ }^{2}, \mathbf{M ~ V i s w a m b a r a n}^{3}$, Vijay Kumar $\mathbf{R}^{4}$ \\ ${ }^{1}$ Assistant Professor, ${ }^{2}$ Professor, ${ }^{3}$ Professor, ${ }^{4}$ Assistant Professor, Department of Dental Surgery and Oral Health Sciences, \\ AFMC, Pune, Maharashtra, India
}

Corresponding author: Dr Prashant Awasthi, Department of Dental Surgery and Oral Health Sciences, AFMC, Pune, aharashtra, India

DOI: 10.21276/ijcmsr.2018.3.3.6

How to cite this article: Prashant Awasthi, Subrata Roy, M Viswambaran, Vijay Kumar R. Dealing with challenges of implant failure and complications: case report. International Journal of Contemporary Medicine Surgery and Radiology. 2018;3(3):C25-C27.

\section{A B S T R A C T}

Introduction: The implant-retained overdenture has been advocated as an effective method of rehabilitating the edentulous patient that offers significant benefits over conventional prosthesis. It is important to understand the etiological factors responsible in causing failures and complications during the various clinical procedures associated with the use of this treatment modality. This knowledge aids treatment planning, communicating with the patient, informed consent, and posttreatment care of the implants and prostheses.

Case report: This paper outlines a clinical case demonstrating common complications encountered in implant retained overdentures and suggests how these complications can be managed.

Conclusion: Failure of implant has a multifactorial dimension. Often many factors come together to cause the ultimate failure of the implant.

Key words: Implant, Complications, Failure

\section{INTRODUCTION}

Failures and complications in implant dentistry has risen considerably in recent past. These are more often due to aging, changing health conditions, long-term wear and tear, poor home care and inadequate professional maintenance and inadequate treatment planning. Knowledge regarding the types of complications that can occur with dental implant procedures is an important aspect of treatment planning, dentist patient communication and post treatment care. This case report deliberates on the various complications arising from the implant retained overdenture treatment and how to deal with these challenges.

\section{CASE REPORT}

A 69 year old male patient presented with the complaint of difficulty in chewing food since last four years. History of presenting complaint revealed that the patient got implant placed at private clinic ten years back. Since four years he is unable to chew food due to loose dentures and have difficulty in speech and unaesthetic appearance. Patient has a smoking habit. Examination of old dentures revealed worn off and broken mandibular and maxillary dentures with very poor denture hygiene.

Intraoral examination revealed 06 implants present in maxillary arch and 04 implants present in the mandibular arch (Figure 1). In the maxillary arch three implants had gingival formers attached to them, two of them had worn off ball abutment and one of them had no prosthetic components attached and was partly covered by mucosa. Periimplant mucositis was present around all implants with plaque accumulation. Implant in the region of 13 elicited clinical mobility. In the mandibular arch 04 implants were present in the interforaminal region with all having broken and worn off abutments. Five teeth (46, 47, 48, 36 and 37) were present in the mandibular arch which were carious and periodontally compromised.

Preoperative OPG confirmed all the clinical findings with periimplant bone loss around the implant in 13 region. It also showed a fractured abutment screw present in the implant in 12 region.

Clinical challenges which were posed with the present clinical situation were unknown specifications of existing implants, mobility of implant in 13 region, abutment screw fracture of implant in the region of 12 , hopeless prognosis of existing dentition and broken head of abutments of mandibular implants.

Treatment was planned in phasic manner. In phase I patient was motivated to stop the smoking habit and later extraction of remaining teeth in the mandibular arch was performed. Mobile implant in the maxillary right quadrant was removed. Fractured screw removal from implant in the region of 12 was done with the help of Neo SR Kit (Neo Biotech, fractured screw Removal Kit) which was followed by supportive periimplant therapy. (Figure 2) In Phase II worn off abutments in the maxillary arch were replaced 


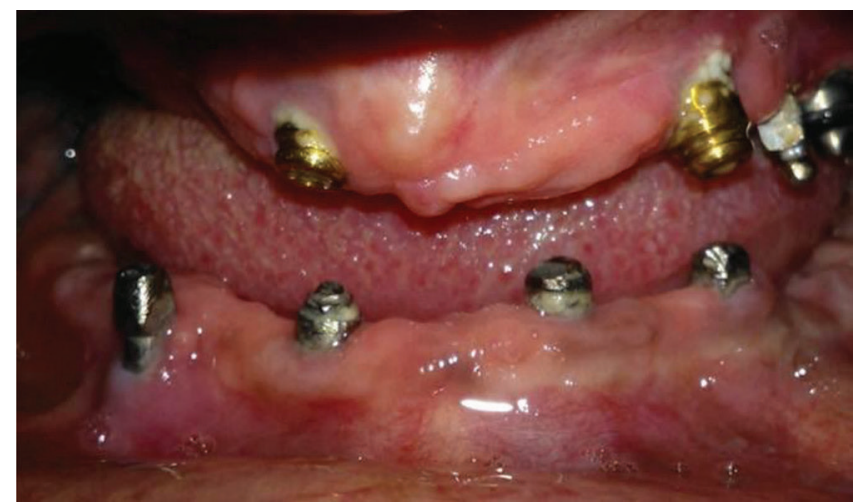

Figure-1: Intraoral preoperative

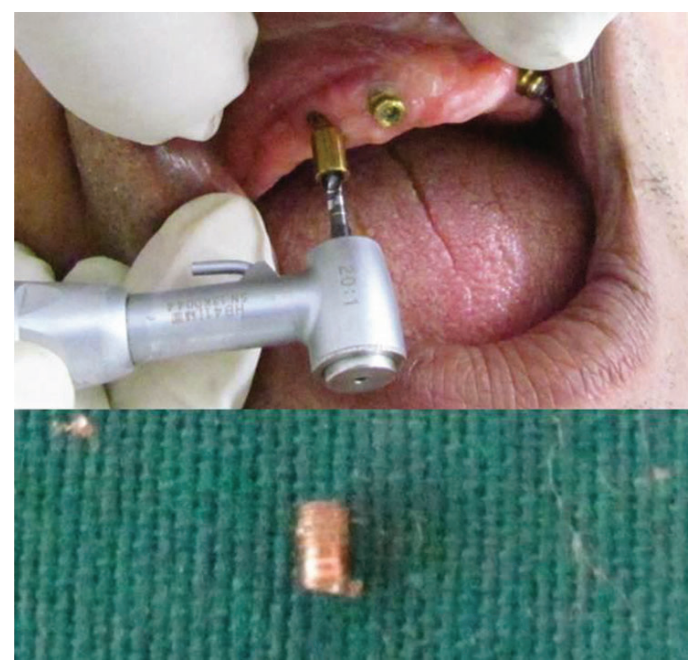

Figure-2: Fractured screw removal from implant in the region of 12

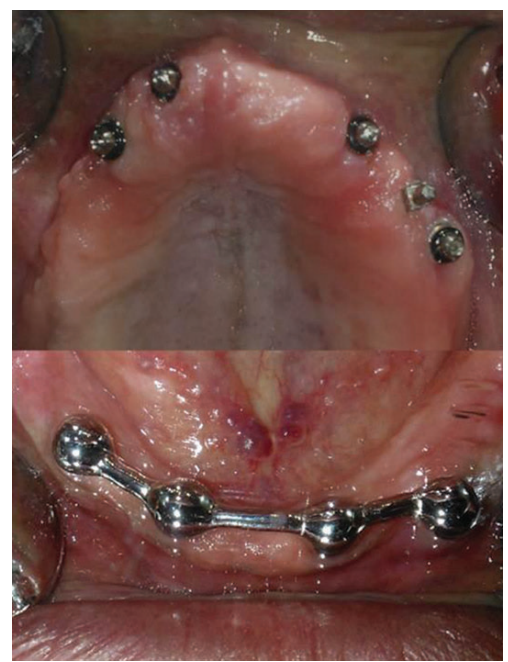

Figure-3: New ball abutments placed in maxillary implants and customized bar cemented on prepared abutments in mandibular arch

by new ball abutments. In the mandibular arch remaining heads of the implants were reshaped and customized bar was fabricated and cemented on to the remaining shaped abutments. (Figure 3) Finally prosthetic rehabilitation was done by conventional implant supported overdenture (RP5) retained by Ball attachments and conventional mandibular overdenture (RP5) retained by bar attachments (Figure 4)

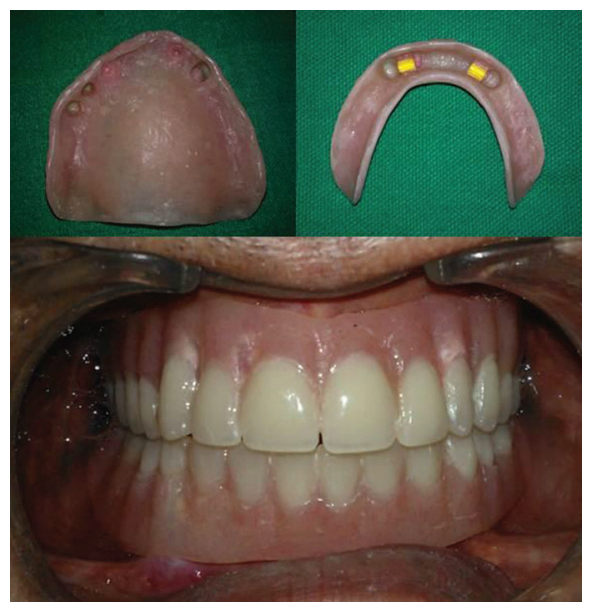

Figure-4: Conventional Implant Supported Maxillary Overdenture Retained By Ball Attachments And Conventional Mandibular Overdenture Retained By Bar Attachments

\section{DISCUSSION}

Implant restorations can fail biologically or mechanically. Biological factors include unsuccessful osseointegration or presence of peri-implantitis. Mechanical failures include crown fracture, framework fracture, screw loosening, and screw fracture.

The present clinical situation illustrates some of the complications inherent in the use of implant treatment. The abutment screw fracture as observed in this case is one of the common complications associated with implant treatment. ${ }^{1,2}$ The most common cause for screw fracture is loosening of the screw aggravated by nonaxial movements during prosthetic loading, culminating in the fracture. ${ }^{3,4}$ Other possible reasons for screw fracture can be a defect in the screw itself, that the screw may have been overtorqued on insertion, or that the abutment may not have been fully seated when the torque was applied to the screw, resulting in increased stress. Reduced interocclusal distance and inefficiency of the operator can also result in screw fracture. ${ }^{5,6}$ Several techniques of removal of a broken abutment screw have been documented, such as engaging an endodontic explorer or a straight probe and ultrasonic scaler. Special screw retrieval systems are also being supplied by various implant manufacturers. In the described clinical situation, the broken abutment screw could not be moved by an explorer or ultrasonic scaler tip hence a screw remover kit from Neo Biotech was used to retrieve broken screw fragment. This universal system has got three main components which are perfect guide, reverse drill and screw remover which are used in sequential manner to retrieve fractured screw fragment. This technique is predictable and applicable to all implant systems and can be effectively incorporated into those clinical situations in which the broken screws are not retrievable by conventional techniques. Peri-implant mucositis describes a reversible inflammatory reaction in the mucosa adjacent to an implant, a term that has become known as implant gingivitis. ${ }^{7}$ Studies show that the prevalence of peri-implant mucositis can be as high as $50 \%$ to $80 \%$ of implants in function ${ }^{9}$ with the etiology of peri-implant mucositis being bacterial plaque. 
Peri-implantitis has been defined as an inflammatory process that affects the tissues around an osseointegrated implant in function and, like periodontitis, results in loss of supporting bone. The prevalence of peri-implantitis has been shown in some studies to range from $11 \%$ to as high as $47 \%$ of implant sites analyzed. ${ }^{10}$ The loss of osseointegration is clinically manifested by a peri-implant radiolucency and implant mobility.

\section{CONCLUSION}

Failure of implant has a multifactorial dimension. Often many factors come together to cause the ultimate failure of the implant. Proper data collection, patient feedback, and accurate diagnostic tool will help point out the reason for failure. An early intervention is always possible if regular check-ups are undertaken.

Diligent and precise surgical and prosthetic procedures are critical to the success of implant therapy, but maintenance of implants may be of equal importance in ensuring long term favorable prognosis.

\section{REFERENCES}

1. Hsu YT, Fu JH, Al-Hezaimi K, Wang HL. Biomechanical implant treatment complications: a systematic review of clinical studies of implants with at least 1 year of functional loading. Int J Oral Maxillofac Implants 2012;27(3):894-904.

2. Goodacre CJ, Bernal G, Rungcharassaeng K, Kan JY. Clinical complications with implants and implant prostheses. J Prosthet Dent 2003;90(5):121-132.

3. Eckert SE, Meraw SJ, Cal E, Ow RK. Analysis of incidence and associated factors with fractured implants: a retrospective study. Int J Oral Maxillofac Implants 2000;15(6):662-667.

4. Spazzin AO, Abreu RT, Noritomi PY, Consani RL, Mesquita MF. Evaluation of stress distribution in overdenture-retaining bar with different levels of vertical misfit. J Prosthodont 2011;20(4):280-285.

5. Quek HC, Tan KB, Nicholls JI. Load fatigue performance of four implant-abutment interface designs: effect of torque level and implant system. Int J Oral Maxillofac Implants 2008;23(2):253-262.

6. Carles J. Goodacre et al. Clinical complications with implant and implant prosthesis. J Prosthet Dent 2003;90:121-32.

7. Albrektsson T, Isidor F. Consensus report of session IV. In: Lang NP, Karring T, ed. Proceedings of the First European Workshop on Periodontology. London: Quintessence, 1994:365-369.

8. Lindhe J,MyleJ.Peri-implant diseases: Consensus report of the Sixth European Workshop on Periodontology. J Clin Periodontology 2008;35(supp1 8): 282-285.

9. Renvert S. Nonsurgical treatment of peri-implant mucositis and peri-implantitis: a literature review. J Clin Perio 2008;35(8 Suppl):305-315.

10. Koldsland $\mathrm{O}$ et al. Prevalence of peri-implantitis related to severity of the disease with different degrees of bone loss. J Perio 2010; 81(2)231-238.

\section{Source of Support: Nil; Conflict of Interest: None}

Submitted: 25-06-2018; Accepted: 18-07-2018; Published online: 07-08-2018 